\title{
Stability Analysis of Host Claystone under T-M Coupling of HLW Disposal Repository in China: Experiments and Numerical Simulation
}

\author{
Haian Liang $\mathbb{D},{ }^{1,2}$ Tan Tang $\mathbb{D},{ }^{1}$ Longpeng Zhang $\mathbb{D}^{1},{ }^{1}$ Xiaodong Liu, ${ }^{1,2}$ Shuai Liu $\mathbb{D},{ }^{1,2}$ \\ Ting Yang $\mathbb{1},{ }^{1,2}$ Xinjun Cheng $\mathbb{D},{ }^{1,2}$ and Juan Zhang $\mathbb{1}^{1}$ \\ ${ }^{1}$ School of Civil and Architectural Engineering, East China University of Technology, Nanchang 330013, China \\ ${ }^{2}$ State Key Laboratory of Nuclear Resources and Environment, East China University of Technology, Nanchang 330013, China \\ Correspondence should be addressed to Haian Liang; haliang@ecut.edu.cn
}

Received 22 June 2021; Accepted 24 August 2021; Published 16 September 2021

Academic Editor: Zhongqiong Zhang

Copyright (C) 2021 Haian Liang et al. This is an open access article distributed under the Creative Commons Attribution License, which permits unrestricted use, distribution, and reproduction in any medium, provided the original work is properly cited.

\begin{abstract}
This paper focuses on the stability of the high-level radioactive waste (HLW) in the proposed clay rock in Tamusu area of China. The in-situ stress as well as the variational characteristics of ambient temperature caused by nuclide decay during HLW storage should be noticeable. A series of thermal property tests and thermo-mechanical coupled strength (T-M) tests of rock samples in the target formation are carried out. Then the stability of surrounding rock of an HLW under the combination of heat release from HLW and in-situ stress is simulated and analyzed by numerical method. Thermal properties of Tamusu clay rock samples are obtained by testing their thermal conductivity. In order to obtain the characteristics and the failure modes of rock samples at different temperatures, the T-M coupling experiments in the temperature range of $100^{\circ} \mathrm{C}$ are conducted. Numerical model for simulating the state of operation of the nuclear waste tank buried in the tunnel within 100 years is constructed. A thermal boundary by the heat release equation of HLW and the real in-situ stress level in Tamusu area are considered in the model. While, the variation law of surrounding rock's temperature, stress, and deformation corresponding to the embedding time is obtained from the numerical calculation. Finally, the stability of the deep geological repository is comprehensively evaluated. The results show that the temperature has a significant impact on the T-M coupling characteristics of Tamusu clay rock, and the proposed repository numerical model has no large deformation and failure problems in 100 years. However, the temperature of the surrounding rock of the repository may exceed the safety standard value during the operation period.
\end{abstract}

\section{Introduction}

HLW has been generated form the defence nuclear industry and nuclear power plants in China. A lot of spent fuel need to be disposed of safely. Clay rock is one of the two preselection disposal surrounding rocks [1]. There are abundant studies on the physical and mechanical macro laws, micro and permeability characteristics of clay rock [2, 3]. However, the interaction between deep geological disposal of HLW and geological environment is one of the urgent problems still need to be solved in the world. It turns out that the longterm stability of the deep geological disposal repository is mainly affected by the in-situ stress condition and the heat released by the HLW.
A number of disposal repositories in clay rock are mainly studied in Belgium, Switzerland, France and China. Belgium built the HADAS (High Activity Disposal Experimental Site) underground laboratory in 1980 [4]. Small -scale, large-scale and full-scale field heating tests have been completed. Gong et al. [5] optimized the Drucker Prager (DP) constitutive model, by using ABAQUS and Boom clay T$M$ coupled experiment. Then, they made use of the D-P model of ATLAS III virtual simulation for the heating test and success. In 1995, Mont Terri URL was built and worked on Opalinus Clay. Favero et al. [6] gave an excellent explanation from the perspective of volume strain that temperature rise would lead to accelerated consolidation of Opalinus clay. After the Meuse/Haste-Marne pre-selection site was 


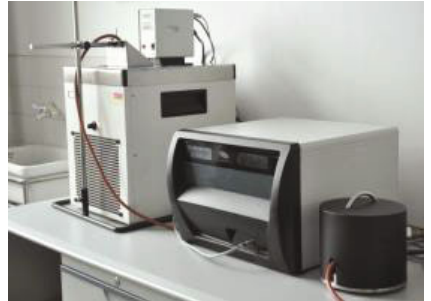

(a)

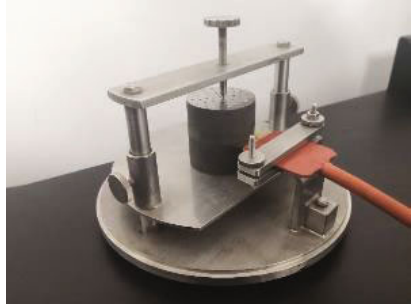

(c)

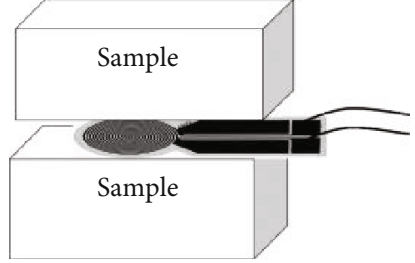

(b)

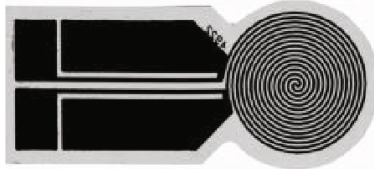

$(\mathrm{d})$

FIgure 1: Thermal constant analyzer and test principle: (a) Hot Disk Thermal Constant Analyzer (TPS2500s); (b) The heat source probe forms a sandwich structure with the sample; (c) Sample testing; (d) Plane heat source probe.

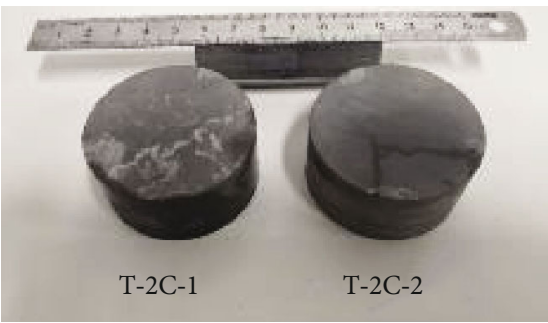

(a)

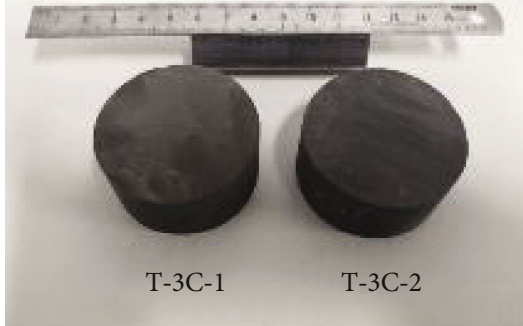

(c)

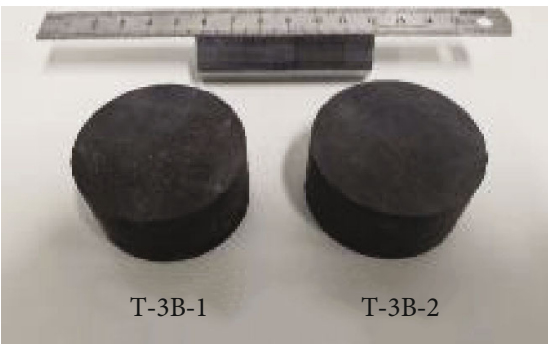

(b)

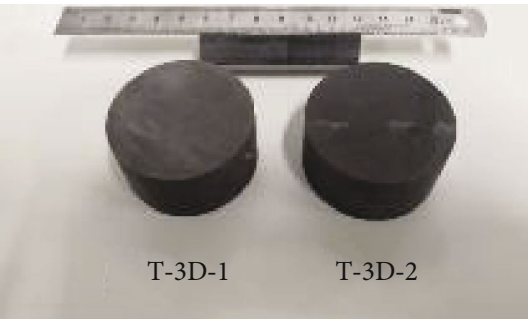

(d)

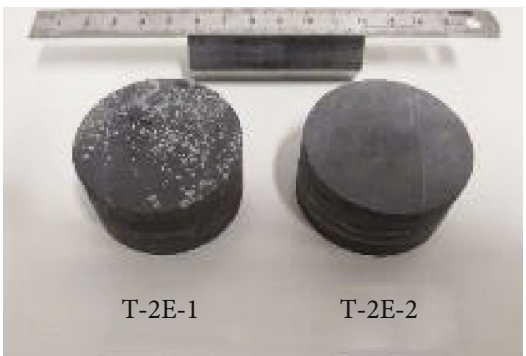

(e)

Figure 2: Test specimen for thermal conductivity of clay rock: (a) Sample No. T-2C-1 and T-2C-2; (b) Sample No. T-3B-1 and T-3B-2; (c) Sample No. T-3C-1 and T-3C-2; (d) Sample No. T-3D-1 and T-3D-2; (e) Sample No. T-2E-1 and T-2E-2. 


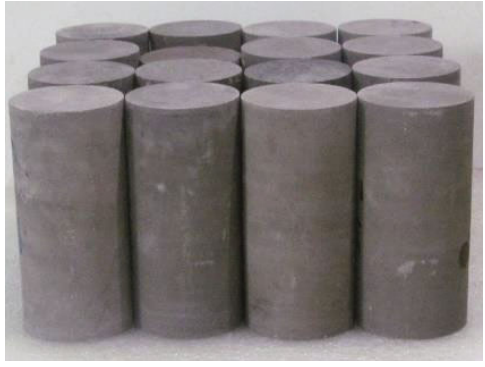

(a)

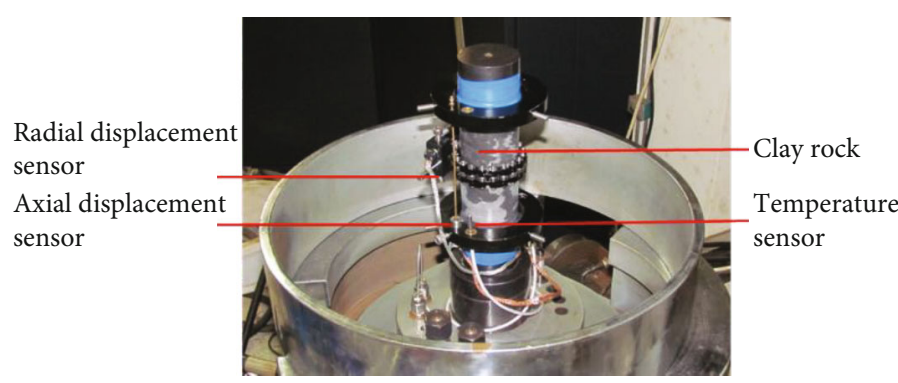

(b)

FIgURE 3: Clay rock samples and sensor installation method (a) Clay rock sample; (b) LVDT and temperature sensor installation.

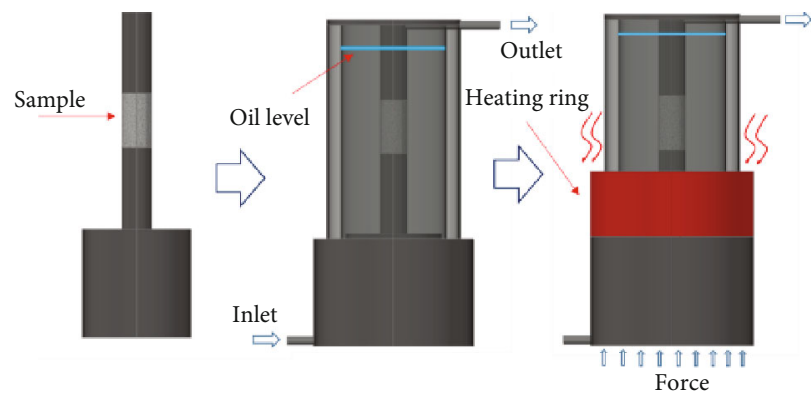

(a)

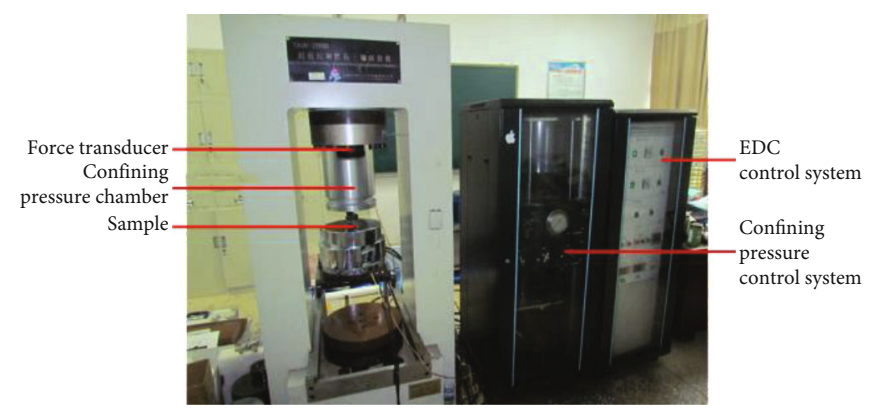

(b)

Figure 4: T-M coupled test principle diagram and triaxial testing machine: (a) Schematic diagram of the T-M coupled tests; (b) TAW-2000 servo-controlled rock triaxial testing machine.

determined in 2000, France built an underground laboratory for the disposal of HLW repository in the Callovo-Oxfordian claystone layer, which is $450 \mathrm{~m}$ underground [7]. Conil and Samat $[8,9]$ evaluated in situ T-M coupled characteristics of the claystone by combining numerical simulation with laboratory test, and finally achieved the purpose of using numerical simulation to guide field test. Nonetheless, there is no real disposal HLW repository has been built in China, most of the past researches have been carried out through sample tests or numerical simulations. There is no clear indication about the T-M coupled characteristics of Tamusu clay rock and the stability of a disposal repository. In studies to date, He et al. [10] found that the influence of temperature on the elastic modulus of clay rocks increased firstly and then decreased, and the inflection point appeared around $85^{\circ} \mathrm{C}$. The T-M coupled experimental study of Liang et al. [11] demonstrated that clay rock presents brittle deformation as a whole, and the high temperature and high pressure can make it possess plastic deformation characteristics.

It can be difficult to infer the stability of disposal repository under T-M coupling. In view of this, our work selects the clay rock of Tamusu in the design layer of the disposal repository as the research object. Firstly, the thermal conductivity of specimens is determined by Hot Disk Thermal Constant Analyzer. What's more, the stress and temperature conditions are reappeared as far as possible in the T-M coupled tests. Finally, heat conductivity, linear expansion rate and mechanical parameters of rock are introduced into FLAC3D numerical simulation software to comprehensively analyse stability of surrounding rock under T-M coupling condition. The experiment and numerical simulation results conform to the objective laws, it can be a useful guideline for China's design and construction of deep geological disposal repository.

\section{Research and Method}

2.1. Materials and Methods of Thermal Test. As an important physical parameter in the T-M coupled research, the thermal properties of the clay rocks in Tamusu are obtained by Hot Disk Thermal Constant Analyzer (TPS2500S) (see Figure 1(a)). A thin disk-shaped temperature-dependent resistor in the instrument is used as a sample probe to test the sample. The probe is a thin sheet of continuous double helix structure (see Figure 1(d)). The outer Kapton protective layer is only $0.025 \mathrm{~mm}$ thick, which can offer the probe a certain mechanical strength while maintaining electrical insulation between the probe and the sample. To form a sandwich-like structure, the probe is sandwiched between two samples before the test. (see Figure 1(b), 1(c)).

In order to obtain the basic thermal conductivity of Tamusu clay rock, five groups of samples are processed and polished by rock cutting machine and double-end grindstone machine (Figure 2(a)-2(e)). Then, the thermal conductivity is tested by Hot Disk thermal constant analyzer (TPS2500 S). Because the thermal conductivity of water $(0.58 \mathrm{~W} / \mathrm{mK})$ is much lower than that of clay rock [12], it has no obvious effect on that, so the thermal conductivity test is only carried out on clay rock samples under dry condition. The indoor temperature is kept constant $\left(22.5^{\circ} \mathrm{C}\right)$. 


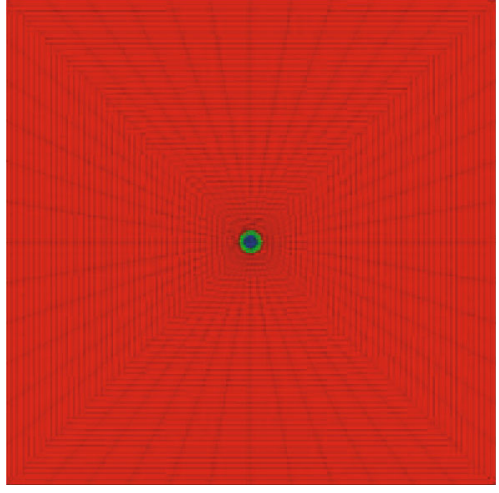

(a)

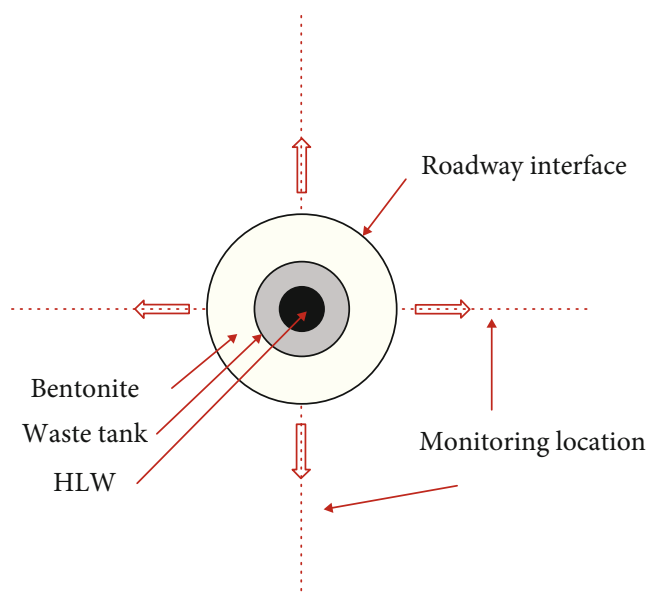

(b)

FIgURE 5: Disposal depot numerical model and monitoring point location schematic diagram: (a) Numerical model of tunnel with nuclear waste tank; (b) Schematic diagram of numerical model monitoring point layout.

TABle 1: Calculation parameters of Tamusu clay rock.

\begin{tabular}{lc}
\hline Parameters & Numerical value \\
\hline Density $\left(\mathrm{kg} / \mathrm{m}^{3}\right)$ & 2441 \\
Coefficient of heat conduction $(\mathrm{W} / \mathrm{mK})$ & 1.38 \\
Specific heat capacity $(\mathrm{J} / \mathrm{kgK})$ & 620.4 \\
Linear expansion coefficient $\left(10^{-5} /{ }^{\circ} \mathrm{C}\right)$ & 2.4 \\
Bulk modulus $(\mathrm{GPa})$ & 5.2 \\
Shear elasticity $(\mathrm{GPa})$ & 4 \\
Cohesion $(\mathrm{MPa})$ & 6.9 \\
Internal friction angle $\left({ }^{\circ}\right)$ & 42.15 \\
Strength of extension $(\mathrm{MPa})$ & 3.36 \\
\hline
\end{tabular}

Each pair of samples is measured at least three times, and the average value is taken as the test result. Before measuring the thermal conductivity of the rock samples, all the specimens are put into a constant temperature drying oven for drying treatment according to the method recommended by the International Society of Rock Mechanics. After weighing, the specimens are put into a dry dish for the thermal conductivity test.

2.2. Materials and Methods of T-M Coupled Test. All the samples of clay rock are processed in accordance with the requirements of GB/T50266-2013 "Standard for Testing Methods for Engineering Rock Mass", and the samples are processed into a standard rock sample with the size $\Phi 50$ $\mathrm{mm} \times 100 \mathrm{~mm}$ as illustrated in Figure 3(a). Four temperature levels are set in the T-M coupled test, which are $45^{\circ} \mathrm{C}, 60^{\circ} \mathrm{C}$, $75^{\circ} \mathrm{C}$, and $90^{\circ} \mathrm{C}$. According to the in-situ stress level of Tamusu, there are four experimental confining pressures, which are uniaxial, $5 \mathrm{MPa}, 10 \mathrm{MPa}$, and $15 \mathrm{MPa}$, with a total of sixteen groups of samples. Number “TM-5-45" indicates that the confining pressure of the test is $5 \mathrm{MPa}$ and the test temperature is $45^{\circ} \mathrm{C}$. For adapting to the high temperature conditions of this test and monitoring the real deformation modes of rock samples with heating and compression, two sets of linear displacement sensors (LVDT) those can withstand high temperature and maintain higher accuracy (see Figure 3(b)). At the beginning of the test, the oil outlet is kept open during heating to prevent the increase of confining pressure by rising the temperature. This temperature changes of the dimethyl silicone oil in the confining pressure room can be monitored by those sensors, then the heating process of the electric coil can be controlled with the computer program. Temperature rises at a constant rate to a predetermined value and remains for a period of time; We close the oil outlet firstly, then the confining pressure be increased to a predetermined value at a speed of $0.5 \mathrm{kN} / \mathrm{s}$ and keep it constant; Finally, the confining pressure chamber is slid to the load-bearing platform, and the axial load is loaded at a speed of $0.5 \mathrm{kN} / \mathrm{s}$ until the sample is destroyed. In order to reduce the influence of inconsistent loading velocity on the test, the axial loading velocity of triaxial compression is consistent with the uniaxial compression test.

As illustrated in Figure 4(a), it is the test principle of T$M$ coupled test. In order to make the samples evenly heated and get a heating rate constant, a temperature-controlled heating ring is used to heat the dimethyl silicone oil in the confining pressure chamber, and the temperature of the rock is slowly increased. The load is applied by lifting the base. An instrument used in this test is the TAW-2000 microcomputer controlled electro-hydraulic servo rock triaxial testing machine of the School of Civil and Architectural Engineering of East China University of Technology. Figure 4(b) shows the entire instrument. Are able to meet the test required equipment performance and precision requirements.

The axial loading stress is calculated according to Formula (1). Where $\sigma$ is the peak strength; $P$ is the axial peak load; $A$ is the cross-sectional area of the sample.

$$
\sigma=\frac{P}{A}
$$

Axial strain and radial strain are calculated according to 
TABLE 2: Calculation parameters of Waste tank and Bentonite.

\begin{tabular}{lcccccc}
\hline Mediums & $\begin{array}{c}\text { Density } \\
\left(\mathrm{kg} / \mathrm{m}^{3}\right)\end{array}$ & $\begin{array}{c}\text { Coefficient of heat } \\
\text { conduction }(\mathrm{W} / \mathrm{mK})\end{array}$ & $\begin{array}{c}\text { Specific heat capacity } \\
(\mathrm{J} / \mathrm{kgK})\end{array}$ & $\begin{array}{c}\text { Linear expansion } \\
\text { coefficient }\left(10^{-5} /{ }^{\circ} \mathrm{C}\right)\end{array}$ & $\begin{array}{c}\text { Bulk modulus } \\
(\mathrm{GPa})\end{array}$ & $\begin{array}{c}\text { Shear elasticity } \\
(\mathrm{GPa})\end{array}$ \\
\hline $\begin{array}{l}\text { Bentonite } \\
\begin{array}{l}\text { Waste } \\
\text { tank }\end{array}\end{array}$ & 1820 & 1.38 & 200 & 0.4 & 1.29 & 0.31 \\
\hline
\end{tabular}

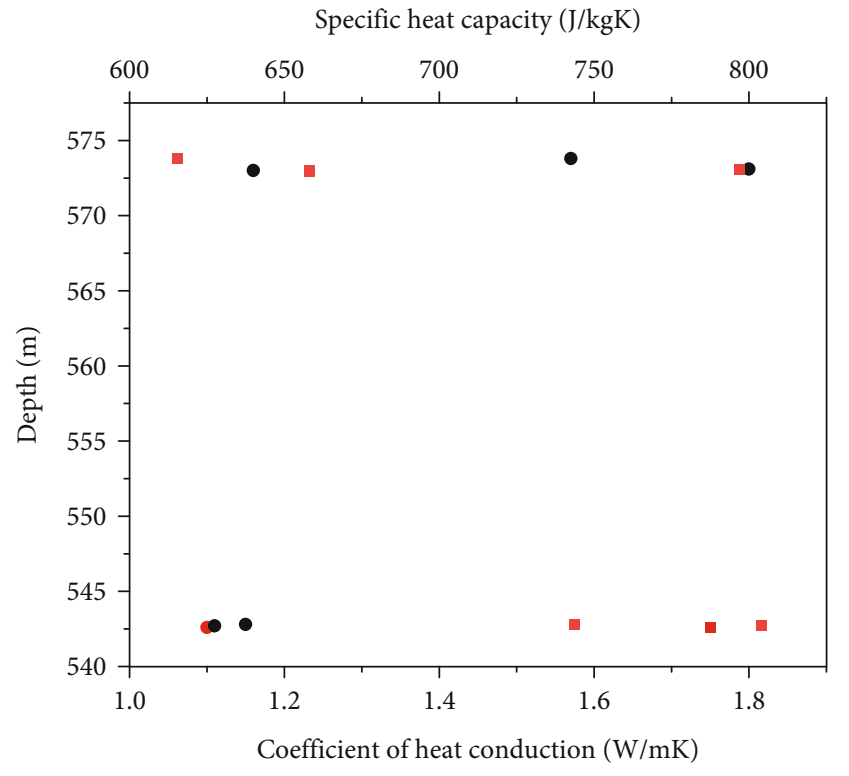

- Coefficient of heat conduction

- Specific heat capacity

Figure 6: Thermal conductivity test results.

Formula (2)-(3). Where $\varepsilon_{1}$ is axial strain, $\Delta L$ is axial deformation; $L$ is the vertical height of the sample; $\varepsilon_{\mathrm{d}}$ is radial strain, $\Delta D$ is radial deformation; $D$ is the diameter of the sample.

$$
\begin{gathered}
\varepsilon_{l}=\frac{\Delta L}{L} \\
\varepsilon_{d}=\frac{\Delta D}{D}
\end{gathered}
$$

Elastic modulus and Poisson's ratio of the sample are calculated according to Formula (4)-(5). Where $E$ is secant modulus; $\mu$ is Poisson's ratio; $\sigma_{50}$ is $50 \%$ of uniaxial compressive strength; $\varepsilon_{l 50}$ is the axial strain value corresponding to the stress $\sigma_{50} ; \varepsilon_{d 50}$ is the radial strain value corresponding to the stress $\sigma_{50}$.

$$
\begin{gathered}
E=\frac{\sigma_{50}}{\varepsilon_{l 50}} \\
\mu=\frac{\varepsilon_{d 50}}{\varepsilon_{l 50}}
\end{gathered}
$$

2.3. Model and Parameters. At present, there is no field test condition in China, evolution characteristics of temperature and deformation of surrounding rock after HLW burial can only be explored through simulation. FLAC 3D is a geotechnical engineering simulation and analysis software with appropriate function of calculation and simulation. It is embedded with a variety of constitutive models of geotechnical materials and widely used in the world. Based on the T-M coupled property of clay rock, we choose Belgian geological disposal depot design model as the numerical model [13-16]. Figure 5(a) shows a disposal roadway model with a horizontal direction, the diameter of the roadway is $2 \mathrm{~m}$, and the diameter of the nuclear waste tank is $0.5 \mathrm{~m}$. The nuclear waste tank is placed in the middle of the disposal roadway, remaining of the space is filled with Bentonite. Without considering the extension on the axis of the roadway, the maximum size of the model is $42 \mathrm{~m} \times 42 \mathrm{~m}$ with a total of 4,514 nodes and 2,256 grids. The relevant parameters of the disposal roadway model are seen Table 1 . The constitutive models of nuclear waste tank and Bentonite materials are, respectively, elastic model and isotropic heat conduction model. The main calculation parameters refer to Liu et al. [17], as illustrated in Table 2. The monitoring point in Figure 5(b) starts from the centre of the disposal tunnel and extends to four directions of the cross section. In the roadway, monitoring points are set at $0.1 \mathrm{~m}$ intervals in the middle part from the waste tank centre to the interface between Bentonite and surrounding rock. Outside the roadway, monitoring points are set at $1 \mathrm{~m}$ intervals in the surrounding rock.

2.4. Stress and Thermal Boundary of Numerical Simulation. In order to scientifically explore the stability of the disposal repository under T-M coupled, setting of thermal boundary and mechanical boundary in numerical simulation is particularly critical. Thermal energy always comes from the heat released by HLW in the waste tank, and exothermic law is applied according to Equation (6). Among the thermal boundaries, four boundaries along axis of the roadway are free and two boundaries perpendicular to the axis of the roadway are non-thermal conductivity boundaries. In terms of initial stress, horizontal initial stress is $15 \mathrm{MPa}$ and vertical initial stress is $13 \mathrm{MPa}$ [18]. Two types of displacement boundary condition, one is that upper, left and right boundary parallel to direction of the tunnel axis are free boundary, which prohibits the deformation ability of the lower boundary in the vertical direction. In addition, the two boundaries perpendicular to the axis of the roadway only prohibit its ability to deform in the horizontal direction. The initial temperature of the clay rock is about $28^{\circ} \mathrm{C}$ (When the surface temperature is $20^{\circ} \mathrm{C}$, the initial temperature of $500 \mathrm{~m}$ underground can be converted according to the ground 
TABLE 3: Comparison of thermal conductivity parameters between Tamusu clay rock and other clay rocks [19-22].

\begin{tabular}{lccc}
\hline Claystone designation & Coefficient of heat conduction $(\mathrm{W} / \mathrm{mK})$ & Specific heat capacity $(\mathrm{J} / \mathrm{kgK})$ & Thermal diffusivity $\left(\mathrm{m}^{2} / \mathrm{s}\right)$ \\
\hline Swiss Opalinus clay & $1.4-1.7$ & 840 & $0.680-0.826$ \\
Belgian boom clay & Horizontal $2.33 /$ vertical 1.77 & 740 & Horizontal $1.3 /$ vertical 0.99 \\
French Callovo-Oxfordian claystone & 1.47 & 785 & 0.774 \\
Clay rock of Tamusu & $1.12 \sim 1.64$ & $610 \sim 778$ & $0.629 \sim 0.959$ \\
\hline
\end{tabular}

temperature gradient of $\left.0.0162^{\circ} \mathrm{C} / \mathrm{m}\right)$. According to the relevant research data of SNFWM in Sweden, the decay and heat release law of the solidified body of HLW [17] can be expressed by Equation (6). Where 1,000a is 1,000 years, $Q(t)$ is the heat source intensity at time $t, Q_{0}$ is the initial heat source intensity, $\mathrm{a}_{1}=7.53 \times 10^{-1}, \mathrm{a}_{2}=2.18 \times 10^{-2}$, $\mathrm{a}_{3}=1.28 \times 10^{-3}$.

$$
\left\{\begin{array}{l}
Q(t)=Q_{0}\left[a_{1} e^{-a_{2} t}+\left(1-a_{1}\right) e^{-a_{3} t}\right], t<1000 \mathrm{a} \\
Q(t)=0.0610798 Q_{0} t, 1000 \mathrm{a}<t<3000 \mathrm{a} \\
Q(t)=0.0206987 Q_{0} t, t>3000 \mathrm{a}
\end{array}\right.
$$

\section{Results}

3.1. Thermal Properties. It can be seen from Figure 6 that the further formation horizon of Tamusu clay rock is from the ground, the better thermal conductivity will be. This can be attributed to the fact that the density increasing of clayey sedimentary rocks and heat transfer mode gradually changes from heat radiation in pores to heat conduction between solids so that the heat transfer is faster with the depth of burial. Apart from depth, pyrite and calcite veins growing in the samples as minerals with more thermal conductivity will enhance this ability of clay rock.

By comparing the surrounding rock of HLW disposal depot of different countries (see Table 3), it can be discovered that the heat conduction property of Tamusu clay rock is closer to Callovo-Oxfordian Claystone of France and Opalinus clay of Switzerland, but weaker than Belgian Boom clay.

3.2. Strength and Damage Characteristics. Sixteen sets of experiments are completed for exploring the characteristics of T-M coupling test of the Tamusu clay rock. The test results are shown in Table 4.

As shown in Figure 7(a)-7(d), all stress-strain curves of clay samples at uniaxial and three axial compression at $45^{\circ} \mathrm{C}$ are obtained. According to the strain path of the sample, there is no obvious compaction stage in the deformation process. The clay rock failure process is characterized by several distinct deformation stages which include crack initiation, crack propagation, and coalescence. The dropping phenomenon of the curves can verify the brittle failure characteristics of the clay rock. Uniaxial compressive strength is lower than triaxial compression peak of clay rock, and the higher confining pressure is, the stronger strength will be. Because confining pressure can limit the radial deformation of the rock and thus enhances the strength.
TABLE 4: T-M coupled tests result of Tamusu clay rocks.

\begin{tabular}{lccc}
\hline $\begin{array}{l}\text { Sample } \\
\text { number }\end{array}$ & $\begin{array}{c}\text { Compressive } \\
\text { strength } \\
(\mathrm{MPa})\end{array}$ & $\begin{array}{c}\text { Elastic } \\
\text { modulus } \\
(\mathrm{GPa})\end{array}$ & $\begin{array}{c}\text { Poisson's } \\
\text { ratio }\end{array}$ \\
\hline TM-0-45 & 34.57 & 6.42 & 0.18 \\
TM-0-60 & 35.57 & 8.16 & 0.19 \\
TM-0-75 & 38.00 & 7.15 & 0.25 \\
TM-0-90 & 30.48 & 7.67 & 0.13 \\
TM-5-45 & 66.20 & 9.02 & 0.23 \\
TM-5-60 & 64.13 & 8.92 & 0.06 \\
TM-5-75 & 60.94 & 9.63 & 0.19 \\
TM-5-90 & 61.99 & 9.75 & 0.19 \\
TM-10-45 & 80.67 & 8.16 & 0.01 \\
TM-10-60 & 68.61 & 8.44 & 0.20 \\
TM-10-75 & 71.36 & 9.48 & 0.18 \\
TM-10-90 & 81.79 & 5.38 & 0.18 \\
TM-15-45 & 176.69 & 17.53 & 0.23 \\
TM-15-60 & 143.63 & 17.74 & 0.20 \\
TM-15-75 & 79.80 & 6.26 & 0.16 \\
TM-15-90 & 122.92 & 15.72 & $/$ \\
\hline
\end{tabular}

Shear failure is always used to describe the failure mode of this specimen, which is mainly broken along a single failure surface. The uniaxial compression test of the sample at $45^{\circ} \mathrm{C}$ deforms more thoroughly (see Figure $8(\mathrm{a})$ ), which means that the temperature may enhance the deformation capacity of the rock. When the samples are limited by confining pressures of $5 \mathrm{MPa}, 10 \mathrm{MPa}$, and $15 \mathrm{MPa}$, it can be seen from the damage models (see Figure $8(\mathrm{~b})-8(\mathrm{~d})$ ) that the combined actions of confining pressure and temperature always results into a damage mode of a single shear plane.

\subsection{Numerical Simulation Results}

3.3.1. Variation Rule of Temperature Field in Tunnel. Temperature of the three monitoring points shows that the same trend with the running time of the disposal repository (see Figure 9(a)). The temperatures at locations (1) (centre of the waste tank) and (2) (junction of the waste tank and Bentonite) are almost equal; With the continuous heat release of HLW, the temperature of each monitoring point rises rapidly at first and reaches the maximum value in 6.5 years. At this point, temperature of position (1) and (2) are $143^{\circ} \mathrm{C}$, and (3) (the boundary between Bentonite and surrounding rock) is $125^{\circ} \mathrm{C}$. As time passed, all temperatures continue to drop slowly after 6.5 year. When HLW is stored for 100 


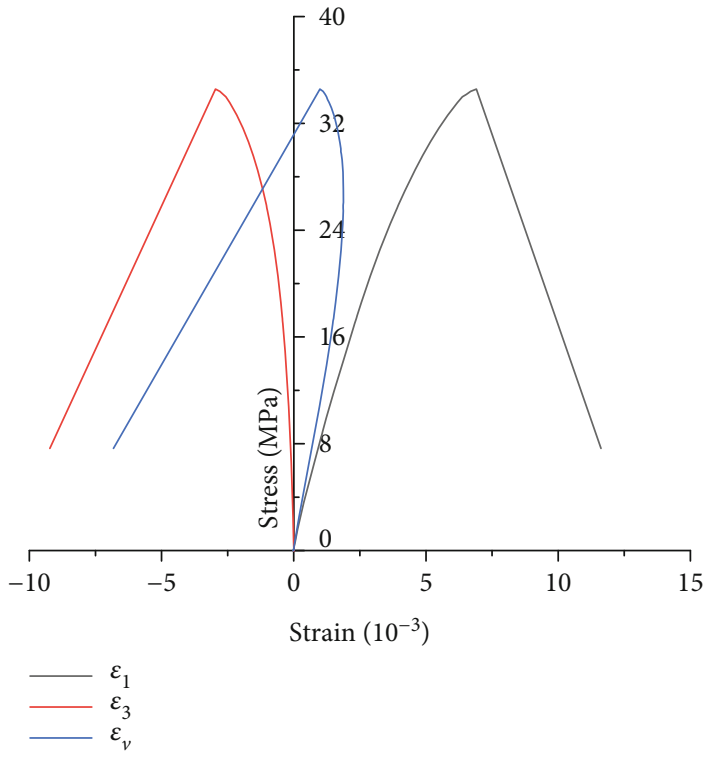

(a)

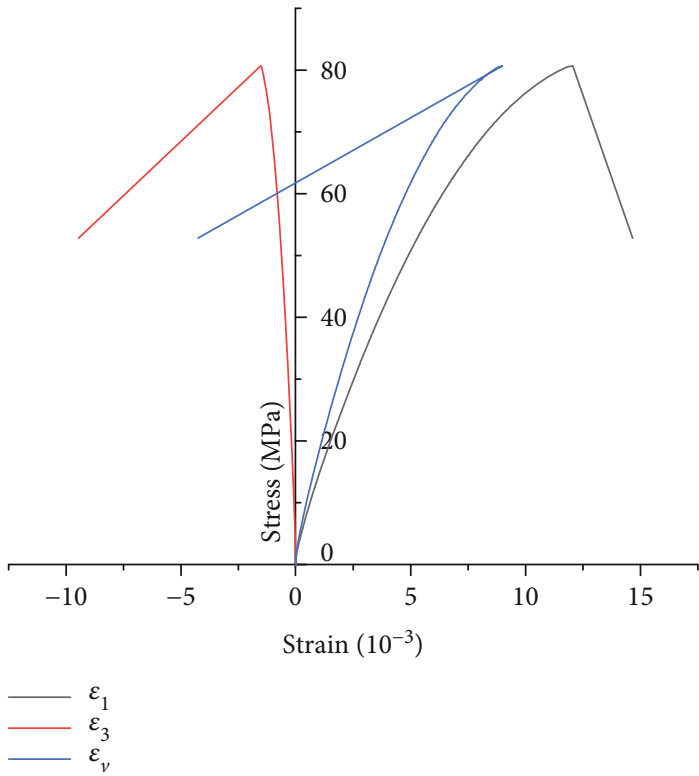

(c)
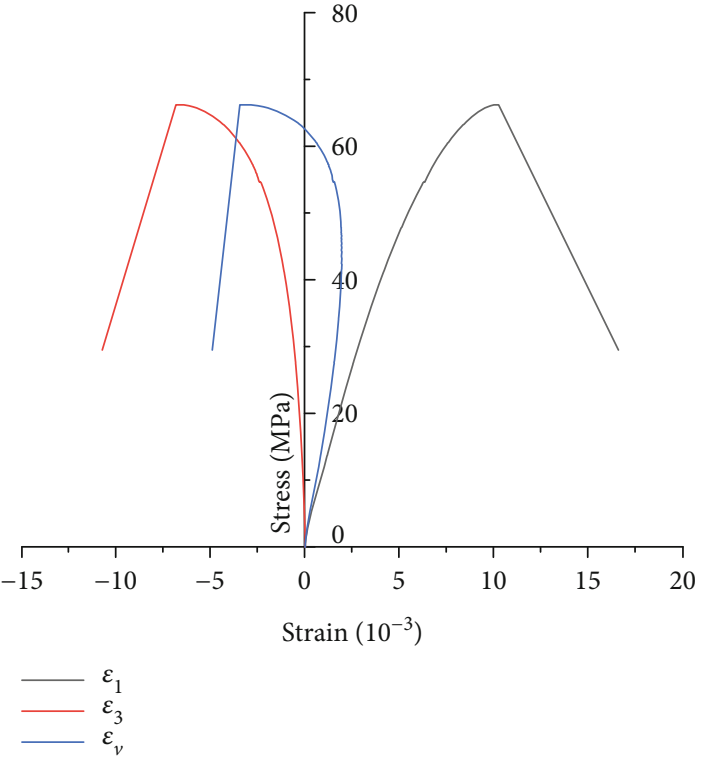

(b)

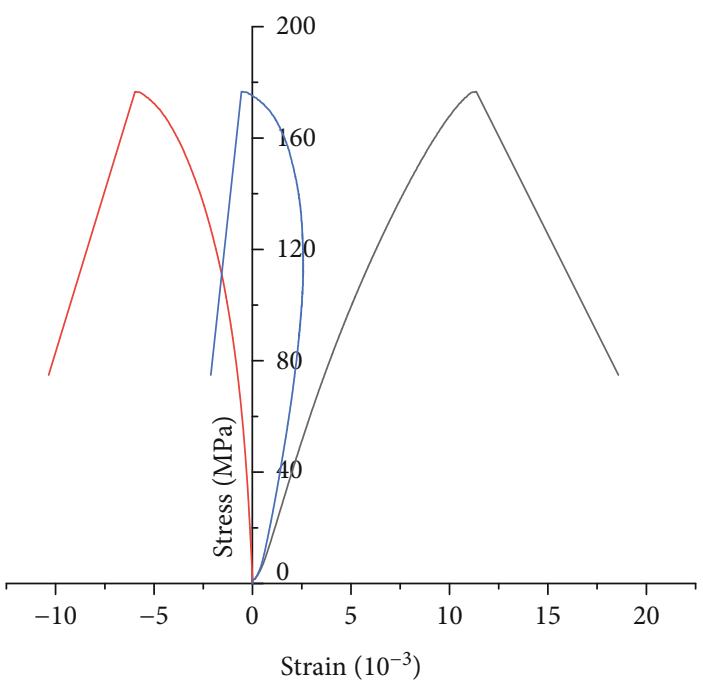

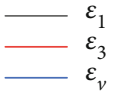

$\varepsilon_{1}$
$\varepsilon_{3}$
$\varepsilon_{v}$

(d)

FiguRE 7: Stress-strain curves of T-M coupled tests results: (a)Stress-strain curve of TM-0-45; (b)Stress-strain curve of TM-5-45; (c)Stressstrain curve of TM-10-45; (d)Stress-strain curve of TM-15-45.

years, the temperature at location (1) is $65.8^{\circ} \mathrm{C}$, and (2) is $68^{\circ} \mathrm{C}$, and (3) is $62^{\circ} \mathrm{C}$.

In Figure 9(b) we can see that after HLW is buried in the disposal warehouse, temperature of all the monitoring points in the waste tank are almost alike. When the thermal energy released from HLW extends outward to Bentonite, it suddenly drops, which is determined by the nature of Bentonite itself. Then the heat energy diffuses into clay rock mass through surrounding rock, and all temperatures of monitoring basically maintain constant at $20 \mathrm{~m}$ away from centre of the roadway. The variation rule between temperature and distance is approximately exponential, and the unique propagation characteristics of temperature in sur- rounding rock are obtained by fitting the data of each group with a function.

3.3.2. Stress Distribution Law of Roadway and Surrounding Rock. The graph of the maximum and minimum principal stresses at positions (2) and (3) (top and bottom of the disposal chamber) have the same change rule with time, and rapidly rise to the peak value within 6.5 years, then slowly weaken (see Figure 10(a), 10(b)). Because the position (1) (the interface between waste tank and Bentonite) is in the tunnel after excavation, and there is no direct contact with the surrounding rock, so the stress is kept in a low state. This also proves that the existence of Bentonite can not only delay 


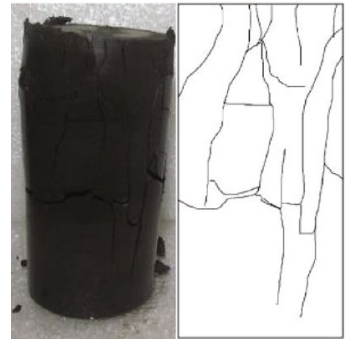

(a) Sample No.1(Uniaxial; $T=45^{\circ} \mathrm{C}$ )

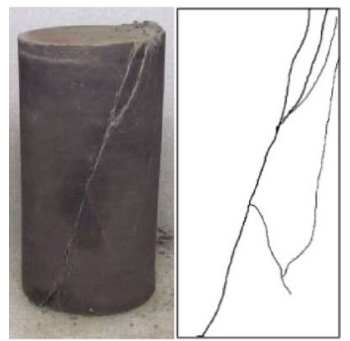

(c) Sample No.3 $\left(\sigma_{3}=10 \mathrm{MPa} ; \mathrm{T}=45^{\circ} \mathrm{C}\right)$

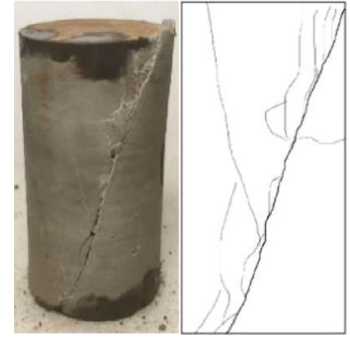

(b) Sample No.2 $\left(\sigma_{3}=5 \mathrm{MP} ; T=45^{\circ} \mathrm{C}\right)$

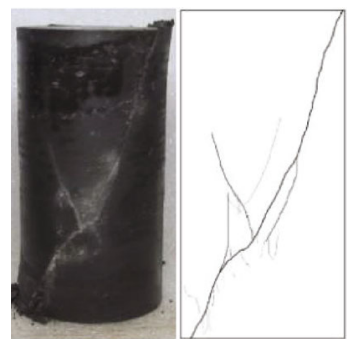

(d) Sample No. $4\left(\sigma_{3}=15 \mathrm{MPa} ; T=45^{\circ} \mathrm{C}\right)$

Figure 8: Before and after T-M coupled test and crack distribution.

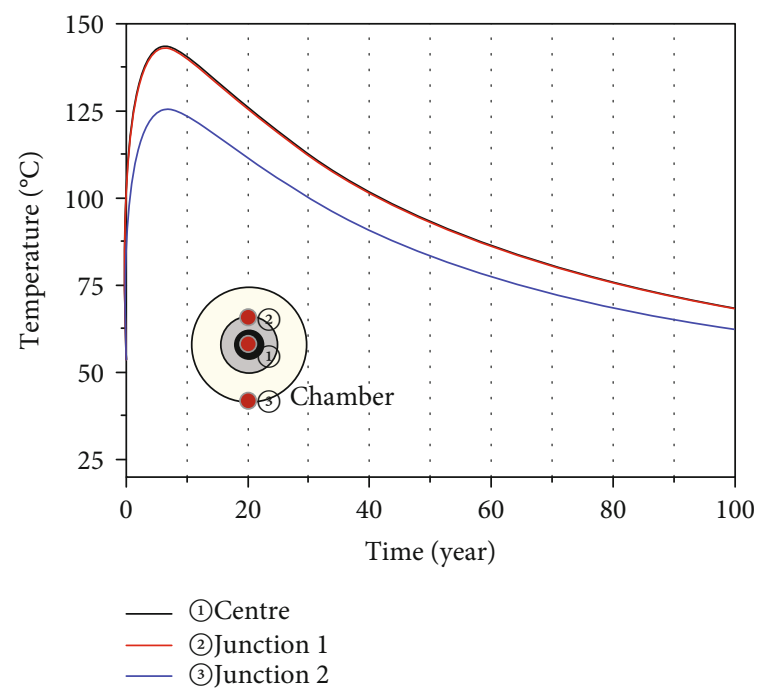

(a)

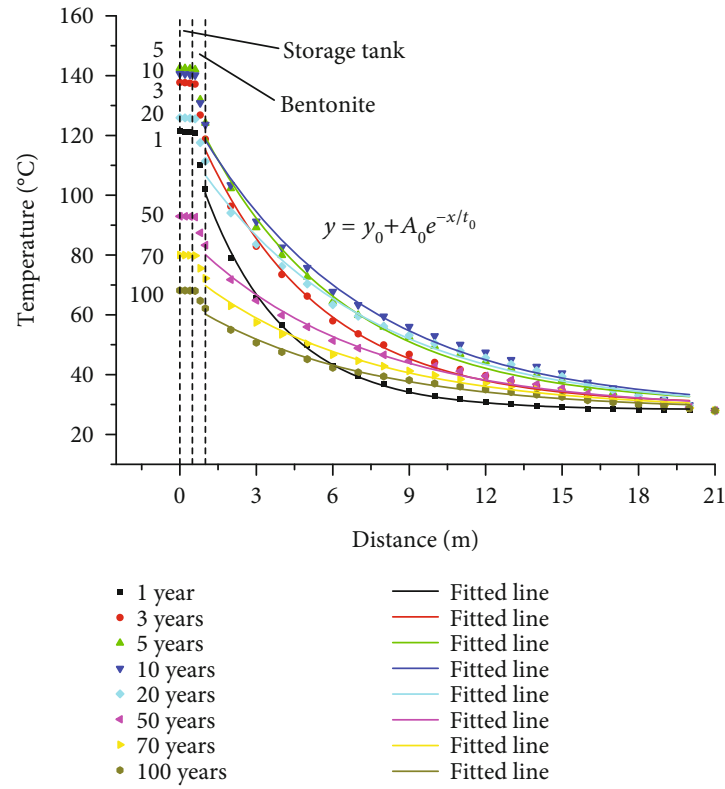

(b)

FIGURE 9: The temperature of the monitoring point changes with time: (a) Temperature change curve with time in roadway; (b) Temperature curve of surrounding rock with distance.

the heating but serve as a buffer layer to reduce the threat of geological tectonic stress to the long-term stability of the disposal repository.

3.3.3. Long-Term Stability Analysis of Disposal Repository. There is no plastic zone in surrounding rock after excavation (see Figure 11(a)) and during 100 years of buried HLW (see Figure 11(b)), it indicates that no damage occurs in the clay rock mass. When the tunnel is excavated without support, the coupled effects of HLW heating and natural stress on the disturbance of surrounding rock are all within the bearing range.

The monitoring points (1)(2) and (3) (4) locate in the upper-lower and left-right directions of the roadway (see Figure 12(a)). Under the action of horizontal principal stress, the surrounding rock on the left and right sides 


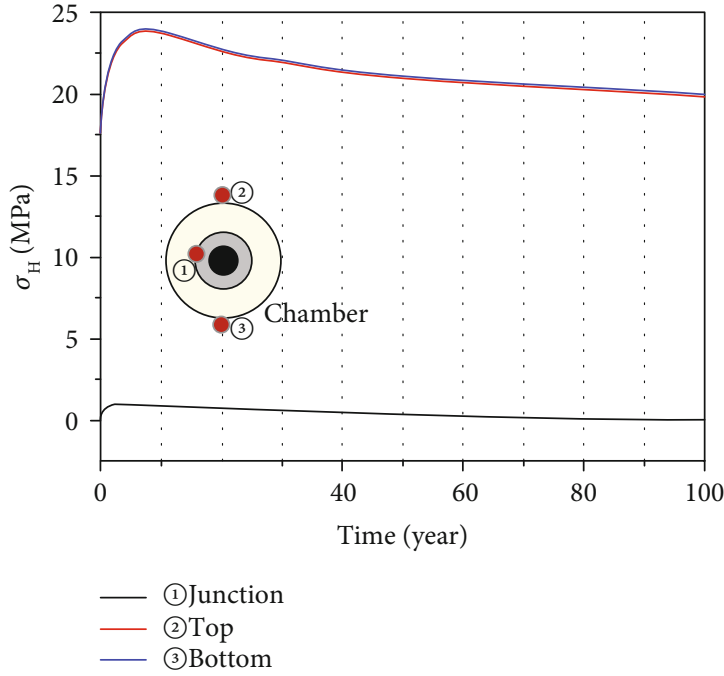

(a)

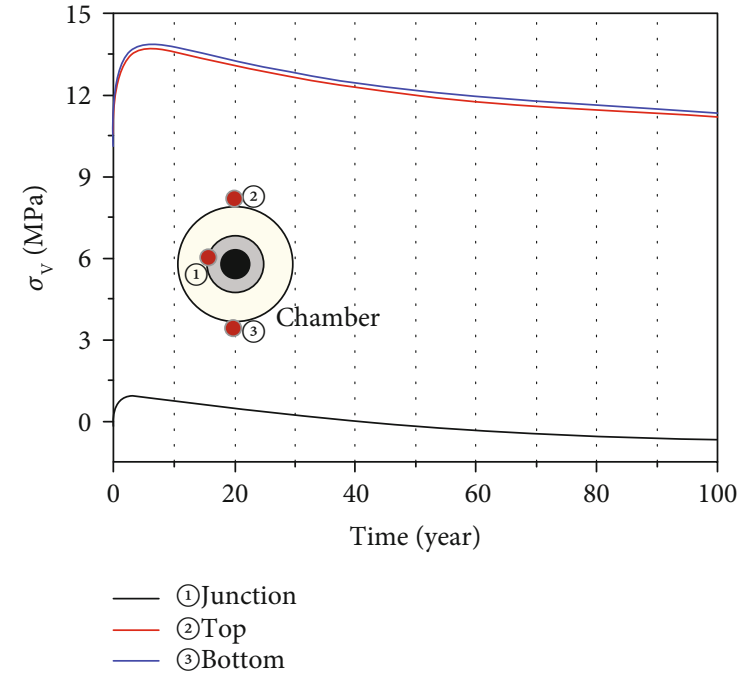

(b)

FIgURE 10: The change curve of principal stress at the monitoring point with time: (a) The relationship between $\sigma_{\mathrm{H}}$ and time; (b) The relationship between $\sigma_{\mathrm{v}}$ and time.

deform into the tunnel after excavation. The deformation at positions (3) and (4) (left and right of the roadway) are symmetrical to the centre of the disposal repository. Deformations at locations (3) and (4) (left and right side of the road) are symmetrical with respect to the centre of the repository and remain basically stable. The deformation at positions (1) and (2) (roof and bottom of the chamber) raise rapidly with time, reaching the peak value in 10 years, then reduce slowly. The variation laws of displacement at positions (1) and (2) verify the rationality of the rules of temperature (see Figure 9(a)) and stress (Figure 10(a), 10(b)). Because the displacement is one of results of T-M coupled, despite the deformation lags behind the stress and temperature at the beginning. According to the classification standard for extrusion deformation of soft surrounding rock in deep caverns, the tunnel convergence strain is adopted to evaluate the stability of surrounding rock when considering the excavation diameter, surrounding rock strength, and in-situ stress, as shown in Figure 12(b). If the strain is less than 2.5\%, there is no trouble about rock mass deformation and stability. The maximum displacement of surrounding rock is $4 \mathrm{~mm}$ (as the Figure 12(a) shows), it means the maximum convergent strain less than $0.4 \%$, so the deformation is within A safe range (see Figure 12(b)). Nevertheless, the clay rock's temperature always rises to $125^{\circ} \mathrm{C}$ within 7 years, which out of the range safety standard of the highest $100^{\circ} \mathrm{C}$ designed.

\section{Discussion}

Laboratorial test results show that the mechanical properties and thermal properties of the clay rock in Tamusu area of China are relatively affected by embedded depth. The elastic modulus, compressive strength and thermal conductivity of the clay rock rise with the increase of buried depth. For another, the damage mode of samples gradually changes from multi-fracture failure to destruct along a single shear plane since the in-situ stress and temperature are rising In this paper, the thermal conductivity of the surrounding rock of the proposed HLW disposal repository as well as the objective law that the thermal conductivity of the surrounding rock grows with the increase of the depth are investigated. It confirms Favero's et al. [6] observation that the higher temperature can lead to the faster consolidation of Opalinus clay. In this article, the thermal conductivity measurement and T-M coupling triaxial tests of the surrounding rock of the proposed nuclear waste disposal repository are carried out, then the thermal and mechanical properties of the clay rock are finally obtained. To a certain extent, these findings may fill the deficiency in the previous studies about the physical and mechanical properties of the Tamusu clay rock as the surrounding rock under the T-M coupling action.

Relevant laws such as engineering properties and expansion properties of the clay rock are revealed through T-M coupling test in the study. Nevertheless, there seems not agree with the rule that the elastic modulus of clay rock should increase at $85^{\circ} \mathrm{C}$ firstly and then decrease as the result of the increase of temperature which is proposed by He et al. [10]. Laboratory test is the key prerequisite for the numerical analysis on the stability of the surrounding rock of the disposal reservoir. Neither the mechanical properties of clay rock under the coupling action of T-M are successional, nor the regularity of mechanical parameters affected by temperature is obvious. What has caused this phenomenon? On the one hand, the rock is the product of geological history, especially the special anisotropy under the influence of geological tectonic movement; On the other hand, the rock samples from Tamusu may be damaged during the sampling process. On the basis of the physical and mechanical parameters, the density and strength of the country rock, and the thermal parameters, i.e., as the linear thermal expansion rate and coefficient of heat expansion obtained from the tests, the numerical model of the HLW disposal reservoir inside the clay rock is constructed. All in all, it can reflect the stability 


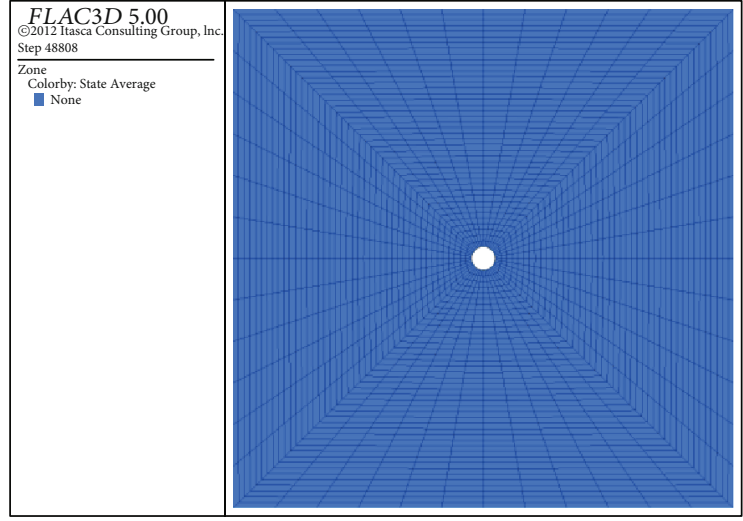

(a)

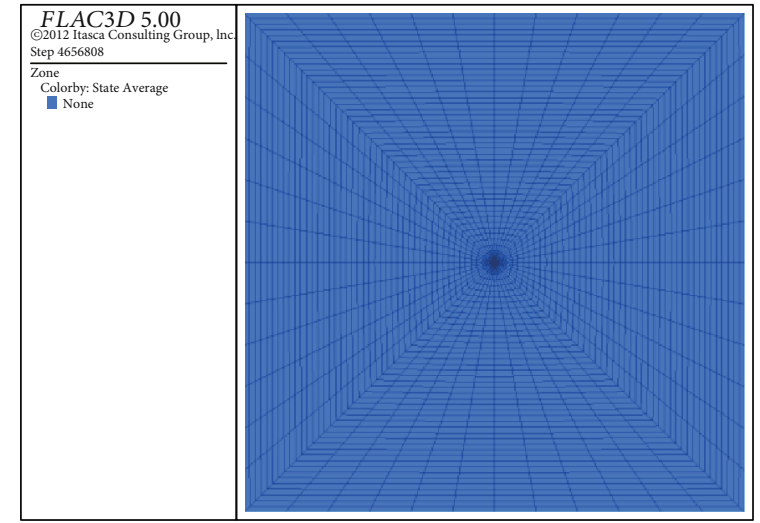

(b)

Figure 11: The plastic zone at different stages of the numerical model: (a) After excavation of tunnel; (b) The tunnel after 100 years of buried waste tank.

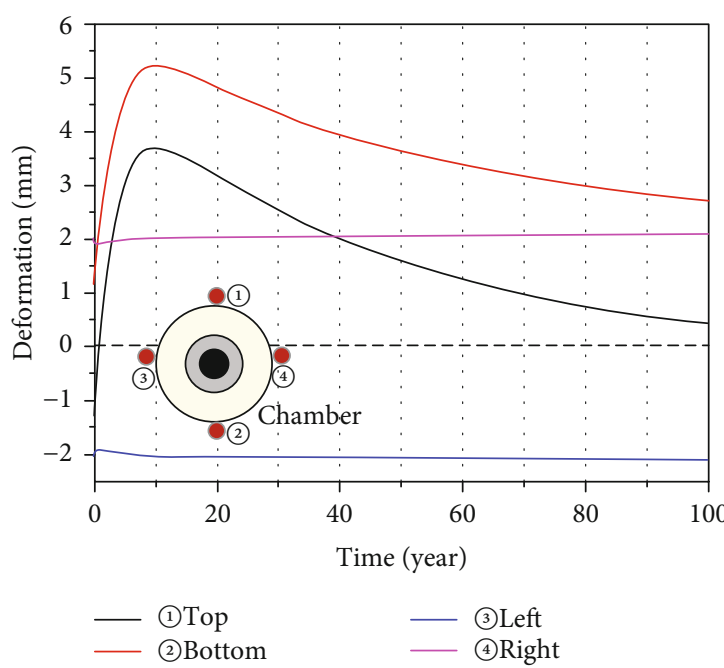

(a)

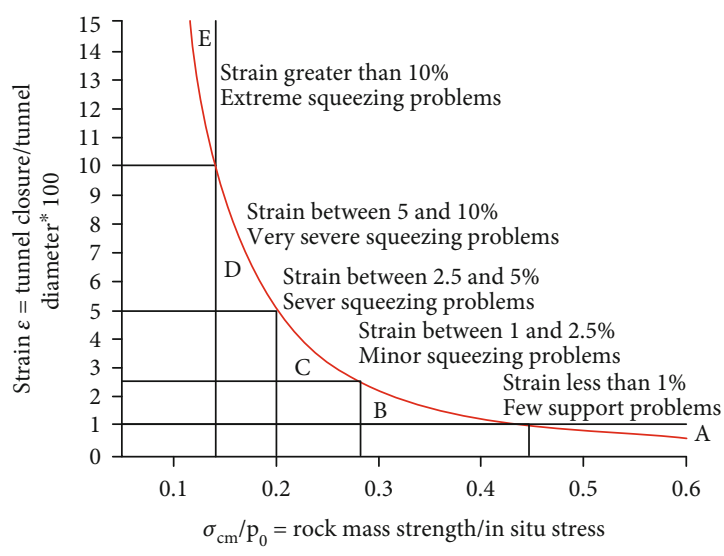

(b)

FIGURE 12: The relation of tunnel deformation with time and the criterion of stability: (a) The relation of tunnel deformation with time; (b) Criterion for judging deformation and global stability of surrounding rock.

problems of HLW disposal under the same condition. Nevertheless, the result of temperature exceeding the safe value obtained from the numerical analysis is closely related to the idealization of HLW storage tank in the numerical model, which is another side that needs to be improved continuously in the subsequent research.

As for future, according to the T-M coupling test results of the Tamusu clay rock, the constitutive relationship reveals the T-M coupling characteristics of the rock should be established. By the way, the long-term stability of a deep geological disposal reservoir is closely related to the creep characteristics of surrounding rock. Therefore, the temperature-creep characteristics of clay rock is also an issue that requires to be settled.

\section{Conclusions}

This paper aims to analyse the stability of clay rock repository through laboratory test and numerical simulation. The main conclusions are as follows.
(1) The thermal conductivity of Tamusu clay is similar with France's Callovo-Oxfordian Claystone and Opalinus clay of Switzerland, but slightly weaker than the Boom clay from Belgium. The failure mode is mainly along a single shear plane. As for uniaxial condition, it is a special splitting damage. Under triaxial compression, the angle between the extension direction of the crack and axis of specimen usually raise with the increase of confining pressure

(2) The results of numerical simulation show that variations of temperature field, stress field, and deformation field of the disposal repository are quite consistent. After excavation, the disposal repository is squeezed into an ellipse by ground stress. Within the time of waste tank is buried, the stress field is affected by the heat release of HLW, which rises to the peak value in 6.5 years and reduces with the decay of heat energy. The displacement of 
surrounding rock both the top and bottom of roadway reach the maximum deformation $(4 \mathrm{~mm})$ in the first 10 years, then basically stabilize

(3) The long-term stability of the disposal repository under the T-M coupled by FLAC3D shows that after roadway excavation and during the 100 -year buried HLW tank, the there is no plastic zone appearing at the numerical model, so the tunnel keeps good security and stability. Whereas, the maximum temperature of the surrounding rock exceeds the safety design value, indicating that the HLW disposal tank still needs to be optimized

\section{Data Availability}

The test data used to support the findings of this study are included within the article.

\section{Conflicts of Interest}

The authors declare that there is no conflict of interest regarding the publication of this paper.

\section{Acknowledgments}

The author should thank the National Natural Science Foundation of China (No. 52168045 and No. 51869002) and the State Administration of Science, Technology and Industry for their support (No. [2014] 1587).

\section{References}

[1] J. Wang, H. Ling, and W. M. Chen, "Study on safety functions of repository for disposal of high level radioactive waste," China Nuclear Power, vol. 10, no. 2, pp. 270-278, 2017.

[2] H. Y. Hu, Mechanical Properties of Clay Rocks from Tamusu Area, East China University of Technology, 2014.

[3] Y. Wang, Experimental Analysis of Hydro-Mechanical Coupling Properties of Clay Rock in the Tamusu Pre-Selected Area, East China University of Technology, 2019.

[4] B. Neerdael and J. P. Boyazis, "The Belgium underground research facility: status on the demonstration issues for radioactive waste disposal in clay," Nuclear Engineering \& Design, vol. 176, no. 1-2, pp. 89-96, 1997.

[5] Z. Gong, W. Z. Chen, H. D. Yu, Y. S. Ma, H. M. Tian, and X. L. $\mathrm{Li}$, "A thermo-mechanical coupled elastoplastic damage model for boom clay," Rock and Soil Mechanics, vol. 37, no. 9, pp. 2433-2442, 2016.

[6] V. Favero, A. Ferrari, and L. Laloui, "Thermo-mechanical volume change behaviour of Opalinus clay," International Journal of Rock Mechanics and Mining Sciences, vol. 90, pp. 15$25,2016$.

[7] J. J. Luo, Z. R. Shang, Q. H. Sun, and Y. F. Kang, “The Study on the Deep Geological Disposal of High-Level Long-ived Radioactive Waste in France and Its Reference to China," Nuclear Safety, vol. 25, no. 3, 2009.

[8] N. Conil, M. Vitel, C. Plua, M. N. Vu, D. Seyedi, and G. Armand, "In situ investigation of the THM behavior of the Callovo-Oxfordian claystone," Rock Mechanics and Rock Engineering, vol. 53, no. 6, pp. 2747-2769, 2020.
[9] S. Samat, L. Brochard, and I. Stefanou, "Magnitude of latent heat in thermally loaded clays," International Journal for Numerical and Analytical Methods in Geomechanics, vol. 44, no. 14, pp. 1926-1957, 2020.

[10] S. He, K. X. Xue, Y. X. Hu, Y. L. Zou, L. C. Chang, and S. P. Li, "On the influence of loading rate and ambient temperature on the mechanics properties of clay rock," Journal of Experimental Mechanics, vol. 25, no. 4, pp. 659-669, 2018.

[11] H. A. Liang, Q. B. Hu, Y. Yang, P. H. Liu, and X. D. Liu, "FLAC3D numerical analysis for the surrounding rock spacing of the disposal repository for high-level radioactive west in the preselected area of clay rock," China Atomic Energy Press, pp. 297-303, 2018.

[12] W. Z. Chen, Z. Gong, H. D. Yu, Y. S. Ma, and H. M. Tian, "Review of thermo-hydro-mechanical coupled tests and constitutive models of clays," Rock and Soil Mechanics, vol. 36, no. 5, pp. 1217-1238, 2015.

[13] X. Zhang, E. Zhai, Y. Wu, D. A. Sun, and Y. Lu, "Theoretical and Numerical Analyses on Hydro-Thermal-Salt-Mechanical Interaction of Unsaturated Salinized Soil Subjected to Typical Unidirectional Freezing Process," International Journal of Geomechanics, vol. 21, no. 7, 2021.

[14] X. L. Li, B. Frederic, and B. Johan, "The Belgian HLW repository design and associated R\&D on the THM behaviour of the host rock and EBS," Chinese Journal of Rock Mechanics and Engineering, vol. 25, no. 4, pp. 681-692, 2006.

[15] X. S. Liu, D. Fan, Y. L. Tan et al., "Failure evolution and instability mechanism of surrounding rock for close-distance parallel chambers with super-large section in deep coal mines," International Journal of Geomechanics, vol. 21, no. 5, p. 04021049, 2021.

[16] Z. Q. Zhang, Q. B. Wu, M. T. Hou, B. W. Tai, and Y. K. An, "Permafrost change in Northeast China in the 1950s-2010s," Advances in Climate Change Research, vol. 12, no. 1, pp. 1828, 2021.

[17] W. G. Liu, J. Wang, H. W. Zhou, C. H. Yang, and P. F. Jang, "Coupled Thermo-mechanical analysis of granite for highlevel radioactive waste repository," Chinese Journal of Rock Mechanics and Engineering, vol. 28, no. S1, pp. 2875-2883, 2009.

[18] H. A. Liang, Q. B. Hu, T. Yang, P. H. Liu, and X. D. Liu, “Analysis on cavern spacing of deep geological disposal of clay rock based on prediction of excavation damage zone," Chinese Journal of Underground Space and Engineering, vol, vol. 16, no. 4, pp. 1153-1162, 2020.

[19] C. L. Zhang, T. Rothfuchs, K. Wieczorek, and N. Jockwer, "Monitoring and modeling of responses of the Opalinus clay to heating," Chinese Journal of Rock Mechanics and Engineering, vol. 25, no. 4, pp. 659-669, 2006.

[20] X. S. Liu, S. L. Song, Y. L. Tan et al., "Similar simulation study on the deformation and failure of surrounding rock of a large section chamber group under dynamic loading," International Journal of Mining Science and Technology, vol. 31, pp. 495505, 2021.

[21] X. S. Liu, D. Y. Fan, Y. L. Tan et al., "New Detecting Method on the Connecting Fractured Zone Above the Coal Face and a Case Study," Rock Mechanics and Rock Engineering, vol. 54, no. $8,2021$.

[22] G. J. Chen, X. Sillen, J. Verstricht, and X. L. Li, “ATLAS III in situ heating test in boom clay: field data, observation and interpretation," Computers and Geotechnics, vol. 38, no. 5, pp. 683696, 2011. 